\title{
Acompanhamento do desenvolvimento global de lactentes com indicadores de risco para perda auditiva
}

\section{Milena D. Ferreira*, Maria C.M.P. Lima}

\begin{abstract}
Resumo
Introdução: O objetivo desta pesquisa foi analisar o desenvolvimento da função auditiva, da linguagem e das condições ambientais para o desenvolvimento motor em lactentes com Indicadores de Risco para Perda Auditiva (IRDA). Métodologia: Foram avaliados 20 lactentes nas idades de 4, 8 e 12 meses por meio de audiometria de reforço visual, pesquisa do reflexo cócleo-palpebral, audiometria comportamental, Escala de Aquisições Iniciais da Linguagem, Protocolo de Avaliação do Sistema Sensório Motor Oral, Escala AHEMD-IS e Caderneta de Saúde da Criança. Os dados obtidos corroboram com a literatura e os lactentes mesmo com indicadores de risco apresentaram um desenvolvimento condizente com sua faixa etária.
\end{abstract}

Palavras-chave: Lactente, Audição, Linguagem Infantil, Desenvolvimento Motor.

\section{Introdução}

A audição é uma habilidade sensorial fundamental no desenvolvimento da criança, tanto em relação à aquisição da linguagem oral, quanto à socialização e a outros comportamentos referentes à comunicação. Portanto, monitorar o desenvolvimento de lactentes com indicadores de risco para deficiência auditiva (IRDA) justifica-se pela importância do diagnóstico precoce de possíveis alterações. O Joint Committee on Infant Hearing $(\mathrm{JClH}, 2000)$ enfatiza que os bebês expostos a IRDA devem ter sua audição monitorada afim de garantir intervenção precoce caso necessário. $O$ objetivo desta pesquisa foi analisar 0 desenvolvimento da função auditiva, da linguagem e das condições ambientais para o desenvolvimento motor em lactentes com (IRDA).

\section{Métodos}

Foram acompanhados lactentes aos 4, 8 e 12 meses de idade no Programa de Monitoramento Auditivo do Centro de Estudos e Pesquisas em Reabilitação (CEPRE). Os lactentes nasceram no CAISM em boas condições de saúde e passaram no teste de Emissões Otoacusticas (EOA). Avaliou-se quatro aspectos: função auditiva (audiometria de reforço visual, pesquisa do reflexo cócleo-palpebral (RCP) e audiometria comportamental), linguagem (Escala de Aquisições Iniciais da Linguagem e Protocolo de Avaliação do Sistema Sensório Motor Oral); desenvolvimento motor com a Escala AHEMD-IS- Affordances in the home environment for motor development e o desenvolvimento global (Caderneta de Saúde da Criança). Os responsáveis das crianças avaliadas assinaram o Termo de Consentimento Livre e Esclarecido (TCLE), permitindo a avaliação e a participação nesta pesquisa, aprovada pelo Comitê de Ética em Pesquisa da UNICAMP, no 2.792.149.

\section{Resultados e Discussão}

Foram avaliados 20 lactentes, sendo os IRDA's mais comuns: histórico familiar para deficiência auditiva, ototoxidade e toxoplasmose.

Observou-se RCP presente em todos os lactentes e o desenvolvimento da função auditiva adequada em todos os lactentes. Foi possível não só avaliar as habilidades da criança, mas também, orientar e mostrar aos responsáveis de modo prático formas de estimular o desenvolvimento auditivo da criança. Barbosa et al (2016) afirmam que crianças que não tiveram resposta de localização de som entre 6 e 18 meses são 1,68 vezes mais propensas a ter a alteração da linguagem entre 2 e 4 anos.

No monitoramento do desenvolvimento da linguagem foi possível observar resultados condizentes com a faixa etária, comprovando que os indicadores de risco devem ser interpretados como possibilidades de prejuízos ao desenvolvimento do indivíduo (Almeida et. al., 2012). Não se observou qualquer evidência relevante, que contribua negativamente para 0 desenvolvimento do sistema estomatognático e para o funcionamento deste em relação à linguagem, contudo, os responsáveis foram orientados sobre como os hábitos deletérios podem beneficiar ou não a criança.

$\mathrm{Na}$ avaliação com o AHEMD-IS destacam que $55 \%$ dos lactentes estão inseridos em ambientes menos adequados em relação às possibilidades de desenvolvimento motor. Tais dados coincidem com o encontrado em outras pesquisas, mostrando que crianças com indicadores de risco muitas vezes encontram-se inseridas em ambientes que podem contribuir negativamente com seu desenvolvimento geral.

\section{Conclusões}

Conclui-se que o monitoramento auditivo e do desenvolvimento global é de grande importância para a verificação de possíveis atrasos e para orientações aos responsáveis acerca do desenvolvimento infantil.

${ }^{1}$ Barbosa, L.L.; Cyntia et al. Relação entre as habilidades auditivas no primeiro ano de vida e o diagnóstico de linguagem em prematuros. Revista CEFAC, v. 18 , n. 6,2016

${ }^{2}$ Northern, J.L.; Downs, M.P. Audição na infância. Guanabara Koogan, 2005

${ }^{3}$ Oliveira, L.N et al. Acompanhamento longitudinal de lactentes com baixo peso ao nascimento: ênfase na aquisição de linguagem. 2002.

${ }^{4}$ Araujo, D.A; Santos, D.C.C; Lima, MCMP. Home environment of infants with risk indicators for hearing los tends to be less stimulating. International Journal of Pediatric Otorhinolaryngology. 2019. 